Original Research

\title{
Availability of cardiac surgical care in surgical correction of acquired heart defects in patients of older age group.
}

\author{
Kubatbek S. Urmanbetov ${ }^{1,2}$, Ivan I. Skopin ${ }^{2}$, Elmira N. Tukusheva ${ }^{1}$ \\ ${ }^{1} \mathrm{SRI}$ of Heart Surgery and Organ Transplantation, Bishkek, Kyrgyzstan \\ ${ }^{2}$ BSCCS "Bakulev Scientific Center of Cardiovascular Surgery" of the Ministry of Health of the Russian \\ Federation, Moscow, Russia
}

\section{Abstract}

Objective: A study of accessibility of surgical care to elderly patients (aged 60 and above) with valvular heart disease has been conducted at the BSCCS "Bakulev Scientific Center of Cardiovascular Surgery" of the Ministry of Health of the Russian Federation.

Methods: A retrospective analysis of structure of hospitalizations of 1726 patients, that were hospitalized between 2009 and 2010 at the BSCCS for surgical correction of valvular heart disease was performed.

Results: Our study demonstrated that age, on one hand, is not the most significant barrier in the geographical accessibility of cardiac surgical care. On the other hand, it can influence the availability in general, taking into account other factors (urban / rural areas, the presence of cardiac surgical clinics, and clinical status). Provision of cardiac surgical care for patients with heart defects at the BSCCS per 1 million population varies considerably in the context of federal districts and is 0.4 for the Siberian Federal District 30 for the Central Federal District (the highest is 42 for the Moscow Region).

Conclusion: Thus, our study demonstrated accessibility of surgical care for elderly patients is the highest for the urban areas with specialized cardiac surgery centers, where patients referred from rural regions.

Key words: Elderly; valvular heart defects; cardiac surgical care

(Heart Vessels and Transplantation 2018; 2: doi: 10.24969/hvt.2017.47)

\section{Introduction}

In the early 1960s, in developed countries of the world there were significant changes in the organization of medical care for patients with acquired valvular heart disease (VHD), which are associated with advances in the surgical correction of heart diseases and are accompanied by increase in the duration and quality of life of this particular group of patients. At the beginning of the $21^{\text {st }}$ century, worldwide, from 250,000 (1) to 280,000 (2) cardiac valvular prostheses were implanted. The number of cardiac valvular prostheses implanted has increased by an average of $5-7 \%$ per year, (biological prostheses by $8-11 \%$, and mechanical prostheses by $3-5 \%$ ) (3).

The urgency of the problem of organizing care for patients with VHD is caused by the fact that the surgical correction of heart defects is a stage of treatment for most patients with VHD and is among the most expensive operations; and the number of adult patients with VHD is progressively increasing worldwide. In United States, despite a $20 \%$ decrease in the total number of hospitalizations over the last twenty years, from 1980 to 2000, the number of hospitalizations with valvular heart disease has quadrupled (4-6). According to Geissler et al. (2005), in Germany, the volume of surgical treatment of acquired heart disease increased significantly from 25,495 cases in 2002 (corresponding to $26.5 \%$ of all heart operations that year) to 33,412 in 2007 (36.5\% of all operations on the heart). In the Russian Federation from 1996 to 2008, the proportion of aortic-valve replacement surgeries has increased by $492 \%$ (543 in 1996 and 2672 in 2008).

Address for Correspondence: Elmira Tukusheva, SRI of Heart Surgery and Organ Transplantation,

Bishkek, Kyrgyzstan, Email: e.tukusheva@mail.ru

Heart Vessels and Transplantation Copyright (C 2018

Received: 05.02.2018 Accepted: 10.03.2018 
Change in the criteria for diagnosis, assessment of the condition can significantly affect the studied indicators.

An important role in the organization of medical care is played by personalized databases, as the information obtained is used to analyze the results of treatment by subgroups, to assess the risk of death, complications, survival and to estimate the costs of treatment, depending on the clinical and demographic characteristics and the scope of interventions. In the Russian Federation, there are no national personalized databases or databases of professional associations. The optimal use of the automated information systems for the optimization of cardiac care is possible if there is an adequate analysis of the classifier and codifier of the surgical and endovascular interventions used in cardiovascular diseases (7).

The purpose of our study is to determine the accessibility of cardiac surgical care for patients with acquired valvular heart defects of the older age group in the BSCCS "Bakulev Scientific Center of
Cardiovascular Surgery" of the Ministry of Health of the Russian Federation.

\section{Methods}

We analyzed records of a sample of 1726 consecutive patients hospitalized between 2009 and 2010 at the BSCCS for surgical correction of the VHD and / or its complications and underwent the valvular heart disease surgery in combination or without coronary artery bypass surgery or the ascending aorta surgery. The structure of hospitalizations depending on the patient's place of residence and age, was analyzed using descriptive statistics, statistics for comparison of categorical variables and Spearman's correlation analysis.

\section{Results and Discussion}

The average age of the patients was $51.4 \pm 12.1$ years (maximum age 79 years). Figure 1 shows the distribution of patients by age.

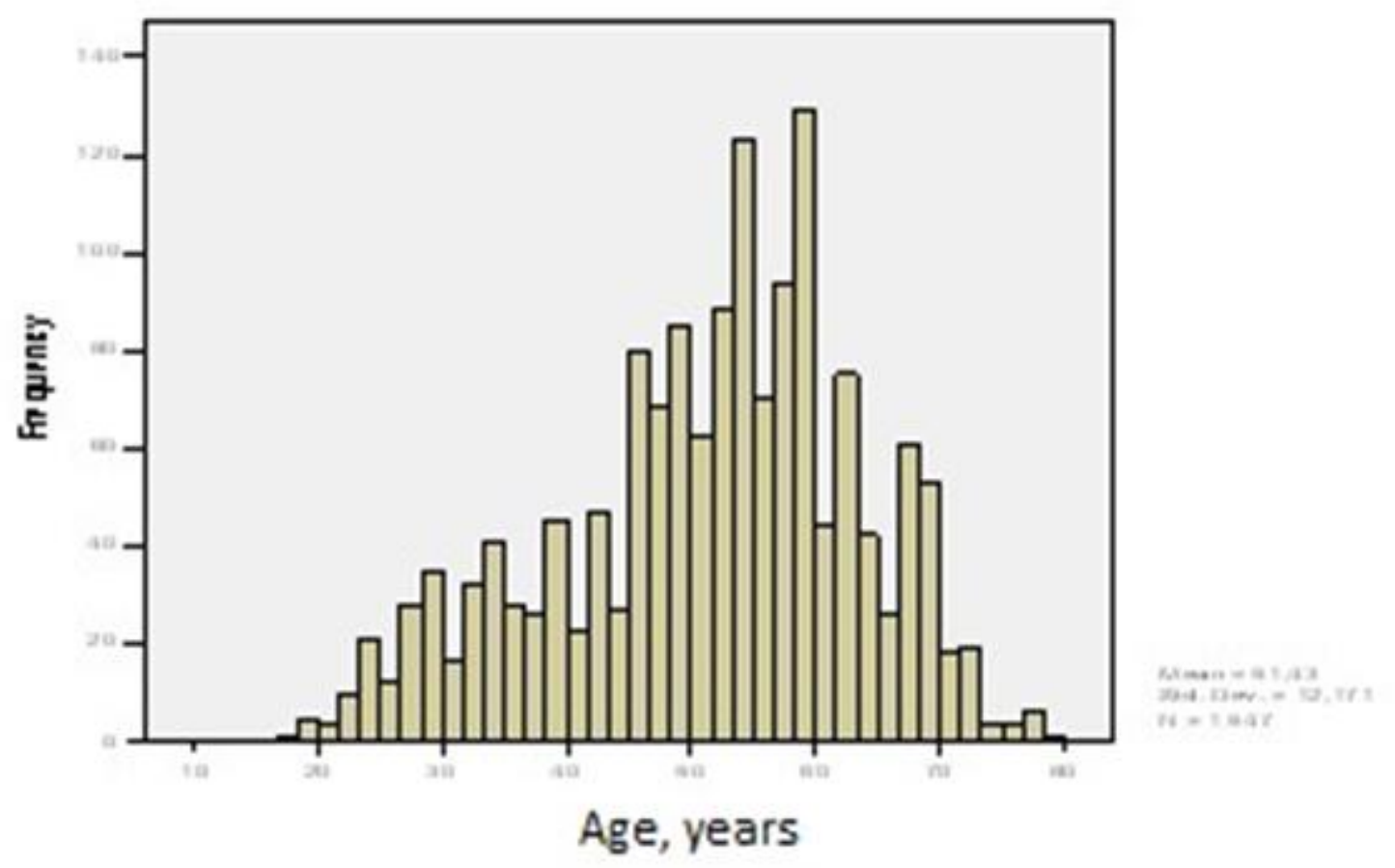

Figure 1. Distribution of patients by age. 
Overall, $45.8 \%$ of study population were women and $54.2 \%$ - men. As can be seen from Table 1, the maximum number of hospitalized patients in our center were referred from the Central Federal District (Moscow, Moscow Oblast and other subjects of the
Central Federal District). However, the distribution of hospitalizations in the districts should not be explained by the problems of geographical accessibility.

Table 1. Structure of hospitalizations depending on the patient's place of residence and age

\begin{tabular}{|l|c|c|c|c|c|c|}
\hline \multirow{2}{*}{ Geographical Region } & \multicolumn{2}{|c|}{ All patients } & \multicolumn{2}{c|}{ Patients $\geq 60$ years } & \multicolumn{2}{c|}{ Patients $\geq 70$ years } \\
\cline { 2 - 7 } & $\mathrm{n}$ & $\%$ & $\mathrm{n}$ & $\%$ & $\mathrm{n}$ & $\%$ \\
\hline Moscow & 401 & 23.2 & 135 & 31.7 & 43 & 38.7 \\
\hline Moscow Oblast & 286 & 16.6 & 83 & 19.5 & 25 & 22.5 \\
\hline $\begin{array}{l}\text { Other regions of Central } \\
\text { Federal District (CFD) }\end{array}$ & 599 & 34.7 & 126 & 29.6 & 30 & 27.0 \\
\hline $\begin{array}{l}\text { North-western Federal } \\
\text { District (FD) }\end{array}$ & 25 & 1.4 & 3 & 0.7 & 0 & 0 \\
\hline Southern Federal District & 202 & 11.7 & 38 & 8.9 & 5 & 4.5 \\
\hline Volga Federal District & 136 & 7.9 & 25 & 5.9 & 4 & 3.6 \\
\hline Ural Federal District & 9 & 0.5 & 2 & 0.5 & 0 & 0 \\
\hline Siberian Federal District & 9 & 0.5 & 4 & 0.9 & 2 & 1.8 \\
\hline Far Eastern Federal District & 17 & 1.0 & 3 & 0.7 & 0 & 0 \\
\hline CIS & 42 & 2.4 & 7 & 1.6 & 2 & 1.8 \\
\hline Total & 1726 & 100.0 & 426 & 100 & 111 & 100 \\
\hline
\end{tabular}

According to the order No.1248, dated December 31, 2009 of the Ministry of Health and Social Development of Russia, the executive branch of the Russian Federation in the field of public health, referral of patients to the specialized centers is done within the planned levels (quotas) of technically wellequipped and high-expertise medical aid centers, provided for by the federal budget funded medical institutions under the Ministry of Health and Social Development of the Russian Federation, the Federal Medical and Biological Agency and institutions that are subordinated by the Russian Academy of Medical Sciences (8).

Table 2 shows the proportion of patients older than 60 years of age among all adult patients underwent VHD surgery at the BSCCS.

It should be noted that in Russia Federation in 2010, according to the Federal State Statistics Service, the share of the population over 60 was $17.7 \%$ (9). Data on subjects and federal districts on the number of people in different age groups and the number of patients with acquired valvular heart disease (including VHD of different etiologies, not only rheumatic heart diseases) is lacking.

The proportion of persons of retirement age in the Russian Federation is $21.6 \%$ including: in the Central Federal District (CFD) - 22.4\%, in Moscow 23.9\%, in the Moscow Oblast 23.6\%; in other subjects of the Russian Federation - 21.3\%, in the North-Western Federal District - 22.8\%; in the Southern Federal District - 20\%; in the Volga Federal District is $21.8 \%$; in the Ural Federal District - 19.5\%, in the Siberian Federal District - $19.5 \%$ and in the Far Eastern Federal District - 18.2\%. 


\begin{tabular}{|c|c|c|c|c|}
\hline \multirow{2}{*}{ Geographical region } & \multicolumn{3}{|c|}{ Patients`distribution by age } & \multirow{2}{*}{ Total } \\
\hline & & $<60$ years & $\geq 60$ years & \\
\hline \multirow{2}{*}{ Moscow } & $\mathrm{n}$ & 244 & 157 & 401 \\
\hline & $\%$ & 60.80 & 39.20 & 100.00 \\
\hline \multirow{2}{*}{ Moscow Oblast } & $\mathrm{n}$ & 197 & 89 & 286 \\
\hline & $\%$ & 68.90 & 31.10 & 100.00 \\
\hline \multirow{2}{*}{ Other subjects of CFD } & $\mathrm{n}$ & 448 & 151 & 599 \\
\hline & $\%$ & 74.80 & 25.20 & 100.00 \\
\hline \multirow{2}{*}{ North-western FD } & $\mathrm{n}$ & 20 & 5 & 25 \\
\hline & $\%$ & 80.00 & 20.00 & 100.00 \\
\hline \multirow{2}{*}{ Southern FD } & $\mathrm{n}$ & 156 & 46 & 202 \\
\hline & $\%$ & 77.20 & 22.80 & 100.00 \\
\hline \multirow{2}{*}{ Volga FD } & $\mathrm{n}$ & 108 & 28 & 136 \\
\hline & $\%$ & 79.40 & 20.60 & 100.00 \\
\hline \multirow{2}{*}{ Ural FD } & $\mathrm{n}$ & 6 & 3 & 9 \\
\hline & $\%$ & 66.70 & 33.30 & 100.00 \\
\hline \multirow{2}{*}{ Siberian FD } & $\mathrm{n}$ & 5 & 4 & 9 \\
\hline & $\%$ & 55.60 & 44.40 & 100.00 \\
\hline \multirow{2}{*}{ Far Eastern FD } & $\mathrm{n}$ & 13 & 4 & 17 \\
\hline & $\%$ & 76.50 & 23.50 & 100.00 \\
\hline \multirow{2}{*}{$\mathrm{CIS}$} & $\mathrm{n}$ & 34 & 8 & 42 \\
\hline & $\%$ & 81.00 & 19.00 & 100.00 \\
\hline \multirow{2}{*}{ Total } & $\mathrm{n}$ & 1231 & 495 & 1726 \\
\hline & $\%$ & 71.30 & 28.70 & 100.00 \\
\hline
\end{tabular}

Comparing the data on the proportion of disabled persons in the Federal Districts with the proportion of patients older than 60 years referred for the surgical treatment of defects at BSCCS, it can be assumed that the age structure of the population of the federation does not determine the age structure of the ones that are hospitalized for surgical treatment of defects. Table 3 shows the proportion of patients older than 70 years of age among all adult patients VHD surgery at BSCCS.
To assess the relationship between the distance from the patient's place of residence and the age when hospitalized for the surgical treatment of defects at the BSCCS, all regions were divided into four groups: Moscow-1, Moscow Oblast -2 , other subjects of the Central Federal District - 3, subjects of other Federal Districts - 4. As can be seen from Figure 2, the age has a weak but reliable negative correlation with the remoteness of the region from BSCCS (Spearman's coefficient is $0.146, p<0.001$ ). 


\begin{tabular}{|c|c|c|c|c|}
\hline \multirow{2}{*}{ Geographical region } & \multicolumn{3}{|c|}{ Patients` distribution by age } & \multirow{2}{*}{ Total } \\
\hline & & $<70$ years & $\geq 70$ years & \\
\hline \multirow{2}{*}{ Moscow } & $\mathrm{n}$ & 350 & 51 & 401 \\
\hline & $\%$ & 87.30 & 12.70 & 100.00 \\
\hline \multirow{2}{*}{ Moscow Oblast } & $\mathrm{n}$ & 258 & 28 & 286 \\
\hline & $\%$ & 90.20 & 9.80 & 100.00 \\
\hline \multirow{2}{*}{ Other subjects of CFD } & $\mathrm{n}$ & 563 & 36 & 599 \\
\hline & $\%$ & 94.00 & 6.00 & 100.00 \\
\hline \multirow{2}{*}{ North-western FD } & $\mathrm{n}$ & 24 & 1 & 25 \\
\hline & $\%$ & 96.00 & 4.00 & 100.00 \\
\hline \multirow{2}{*}{ Southern FD } & $\mathrm{n}$ & 193 & 9 & 202 \\
\hline & $\%$ & 95.50 & 4.50 & 100.00 \\
\hline \multirow{2}{*}{ Volga FD } & $\mathrm{n}$ & 128 & 8 & 136 \\
\hline & $\%$ & 94.10 & 5.90 & 100.00 \\
\hline \multirow{2}{*}{ Ural FD } & $\mathrm{n}$ & 9 & 0 & 9 \\
\hline & $\%$ & 100.00 & 0.00 & 100.00 \\
\hline \multirow{2}{*}{ Siberian FD } & $\mathrm{n}$ & 7 & 2 & 9 \\
\hline & $\%$ & 77.80 & 22.20 & 100.00 \\
\hline \multirow{2}{*}{ Far eastern FD } & $\mathrm{n}$ & 17 & 0 & 17 \\
\hline & $\%$ & 100.00 & 0.00 & 100.00 \\
\hline \multirow{2}{*}{$\mathrm{CIS}$} & $\mathrm{n}$ & 39 & 3 & 42 \\
\hline & $\%$ & 92.90 & 7.10 & 100.00 \\
\hline \multirow{2}{*}{ Total } & $\mathrm{n}$ & 1588 & 138 & 1726 \\
\hline & $\%$ & 92.00 & 8.00 & 100 \\
\hline
\end{tabular}

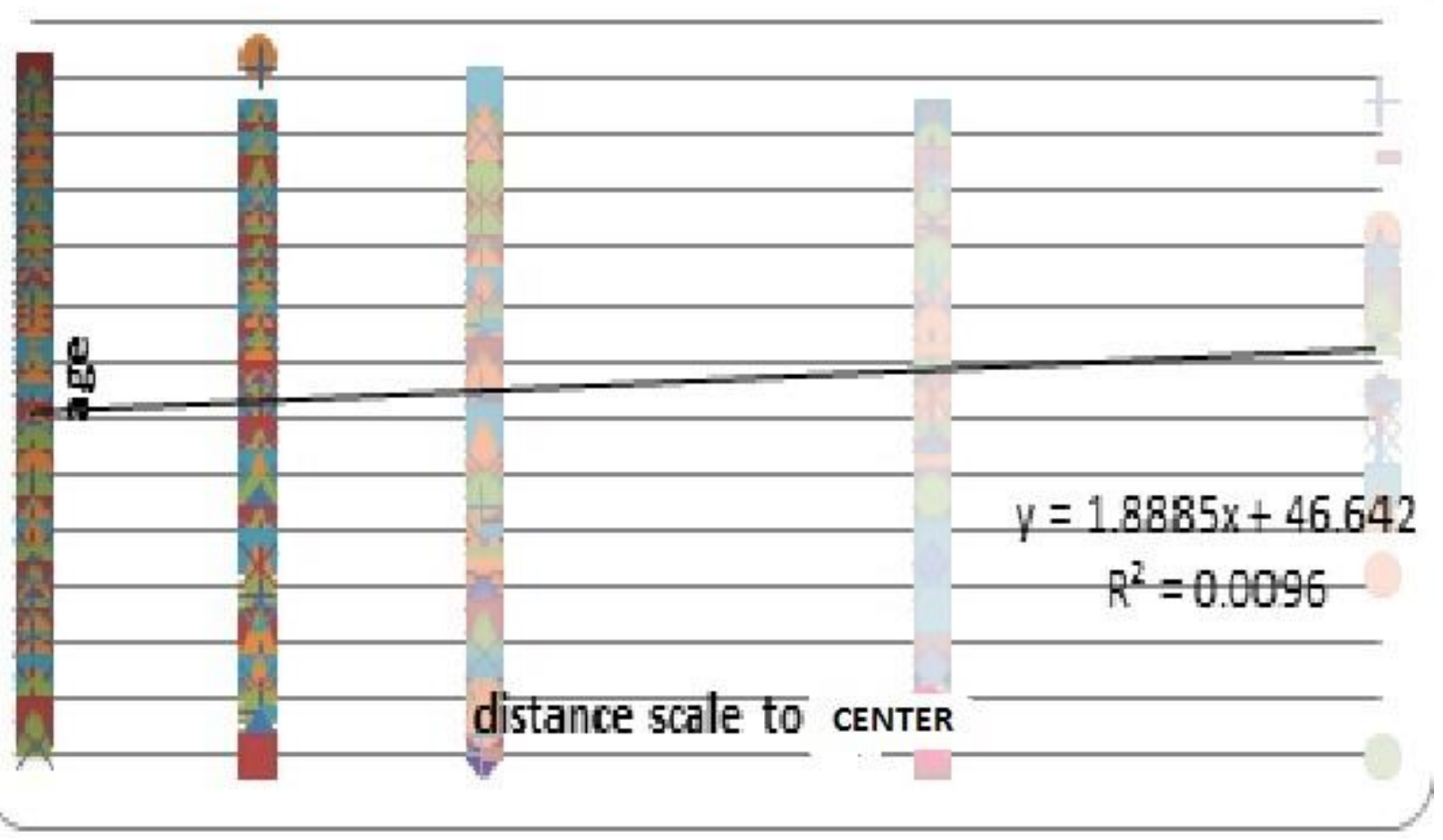

Figure 2. The relationship between the patient's age and the distance scale to BSCCS. 
However, the significance of the correlation coefficient between the age (over 60) and the geographical distance of the patient's residence to BSCCS is high (Spearman's coefficient - 0.45, p<0.001), if we form groups according to such criteria as age over 60 years, and the conventional scale of the distance to the BSCCS is represented in the form of 2 groups (CFD and other districts of the Russian Federation), which is presented in Tables 4 and 5.

\begin{tabular}{|c|c|c|c|}
\hline \multicolumn{4}{|c|}{ Table 4. Distribution of patients by district depending on age } \\
\hline \multicolumn{1}{|c|}{ Age category } & CFD & Other FD & Total \\
\hline Aged $<60$ years, $n(\%)$ & $441(36.8)$ & $756(63.2)$ & $1197(100)$ \\
\hline Aged $\geq 60$ years, $n(\%)$ & $397(81.5)$ & $90(18.5)$ & $487(100)$ \\
\hline
\end{tabular}

The proportion of patients older than 60 years and younger than 60 years differ significantly in 2 groups (CFD and other Russian Federation Federal Districts); their proportion is significantly lower among patients sent from other Federal Districts $(p<0.001)$.
The proportion of patients older than 70 years and younger than 70 years differ significantly in 2 groups (CFD and other Russian Federation Federal Districts); their proportion is significantly lower among patients sent from other Federal Districts $(p<0.001)$.

Table 5. Distribution of patients by district depending on age
\begin{tabular}{|c|c|l|c|}
\hline Age category & CFD & Other FD & Total \\
\hline Aged $<70$ years, $n(\%)$ & $723(46.7)$ & $826(53.3)$ & $1549(100)$ \\
\hline Aged $\geq 70$ years, $n(\%)$ & $115(97.6)$ & $20(2.4)$ & $135(100)$ \\
\hline
\end{tabular}

Thus, taking into account a moderate reliable negative correlation between age and remoteness of the patient's place of residence, significant and reliable differences in the hospitalization rate between patients of different age categories (over 60 years and older than 70 years) from different Russian Federation Federal Districts can be observed. The age, on one hand, is not determinative barrier in the geographical availability of cardiac surgical care. On the other hand, it may affect the availability in general, taking into account other factors (urban/ rural, the presence of cardiac surgical clinics, clinical status). Though we did not include in the analysis other important factors need to be mentioned as volume of surgeries and availability of specialists on cardiac surgery in remote areas, they should be taken in account. As can be seen from the Table 6 , the availability of cardiac surgical care for patients with heart defects at the BSCCS per 1 million population varies considerably. However, within the CFD, Moscow and the Moscow Oblast, these differences are not so pronounced compared to other Federal Districts.

\begin{tabular}{|l|c|}
\hline \begin{tabular}{|l|}
$\mid$ Table 6. Provision of cardiac surgical care for patients with valvular heart disease at the per \\
$\mathbf{1}$ million population
\end{tabular} & Per 1, 000, 000 population \\
\hline Geographical region & 38 \\
\hline Moscow & 42 \\
\hline Moscow Oblast & 30 \\
\hline Other subjects of CFD & 1.8 \\
\hline North-western FD & 8.7 \\
\hline Southern FD & 4.5 \\
\hline Volga FD & 0.7 \\
\hline Ural FD & 0.4 \\
\hline Siberian FD & 2.6 \\
\hline Far eastern FD & \\
\hline
\end{tabular}


The percentage of city residents varies somewhat in different Federal Districts (FD); among patients older than 60 years with the exception of the NorthWestern FD, the proportion of city residents prevails in all FDs; among 70-year-old patients, the proportion of patients from the city prevails for all patients (Table 7).

The age structure of the population does not correlate with the age structure of hospitalized for surgical treatment of defects at BSCCS. The age of patients hospitalized for the surgical treatment of defects has a weak but reliable negative correlation with the remoteness of the region from the BSCCS (Spearman's coefficient is 0.146, $p<0.001$ ).

The proportion of patients older than 60 years is significantly lower among patients sent from "other" federal districts in comparison with the central federal district ( $p<0.001$ ); among patients older than 70 years, the difference is even more significant $(p<0.001)$.

Table 7. Distribution of patients residing in cities by geographic region

\begin{tabular}{|l|c|c|c|c|}
\hline Geographical region & City residents, \% & $\begin{array}{c}\text { City residents } \\
\text { among patients } \\
<60 \text { years old, \% }\end{array}$ & $\begin{array}{c}\text { City residents } \\
\text { among patients } \\
\mathbf{2 6 0} \text { years old, \% }\end{array}$ & $\begin{array}{c}\text { City residents } \\
\text { among patients } \\
\mathbf{2 7 0} \text { years old, \% }\end{array}$ \\
\hline Moscow & 100 & 100 & 100 & 100 \\
\hline Moscow Oblast & 74.8 & 76.6 & 70.8 & 75 \\
\hline Other subjects of CFD & 71.8 & 70.1 & 76.8 & 80.6 \\
\hline North-western FD & 68 & 70 & 60 & 100 \\
\hline Southern FD & 65.8 & 59 & 89.1 & 77.8 \\
\hline Volga FD & 72.8 & 70.4 & 82.1 & 87.5 \\
\hline Ural FD & 77.8 & 66.7 & 100 & - \\
\hline Siberian FD & 88.9 & 80 & 100 & 100 \\
\hline Far eastern FD & 88.2 & 84.6 & & - \\
\hline
\end{tabular}

\section{Conclusion}

Thus, age, on one hand, is not the most significant issue in the geographical accessibility of cardiac surgical care. On the other hand, it can influence the availability in general, taking into account other factors (urban/rural residence, the presence of cardiac surgical clinics, clinical status). Provision of cardiac surgical care for patients with heart defects at the BSCCS per 1 million population varies considerably in the context of federal districts and is 0.4 for the Siberian Federal District and 30 for the Central Federal District (the highest is $\mathbf{4 2}$ for the Moscow Region). Our study demonstrated accessibility of surgical care for elderly patients is the highest for the urban areas with specialized cardiac surgery centers, where patients referred from rural regions.

Peer-review: external and internal

Authorship: K.S.U., I.I.S., E.N.T. contributed equally to preparation of article

Conflict of interest: None to declare

Acknowledgement and funding: None to declare

\section{References}

1. Pibarot P, Dumesnil JG. Prosthetic heart valves. Selection of the optimal prosthesis and long-term management. Circulation 2009; 119: 1034-48.

2. Agabiti N, Cesaroni G, Picciotto S, Bisanti L, Caranci $\mathrm{N}$, Costa $\mathrm{G}$, et al. The association of socioeconomic disadvantage with postoperative complications after major elective cardiovascular surgery. J Epidemiol Community Health 2008; 62: 882-9.

3. Butany J, Ahluwalia MS, Munroe C, Fayet C, Ahn J, Blit $P$, et al. Mechanical heart valve prostheses: identification and evaluation. Cardiovasc Pathol 2003; 12: 322-44.

4. Supino PG, Borer JS, Yin A. The epidemiology of valvular heart disease: an emerging public health problem. Adv Cardiol 2002; 39: 1-6.

5. Geissler HJ, Schlensak C, Sudkamp M, Beyersdorf F. Heart valve surgery today: indications, operative technique, and selected aspects of postoperative care in acquired valvular heart disease. Dtsch Arztebl Int 2009; 106: 224-33. 
6. Bokeria LA, Gudkova RG. Cardiovascular Surgery2007. Diseases and congenital anomalies of the circulatory system. BSCCS, "Bakulev Scientific Center of Cardiovascular Surgery» of the Ministry of Health of the Russian Federation; Moscow 2008. p.144

7.Stupakov IN, Samorodskaya IV, Bokeria LA. Evidence-based medicine and cardiovascular diseases. BSCCS, "Bakulev Scientific Center of Cardiovascular Surgery» of the Ministry of Health of the Russian Federation; Moscow; 2006. p.253
8.Order of the Ministry of Health and Social Development of the Russian Federation No. 1248 of December 31, 2009 "Procedure for sending citizens of the Russian Federation for rendering high-tech medical assistance in 2011".

9. Results of the All-Russian Population Census of 2010. Data of the Federal Service of State Statistics of the Russian Federation. Demoscope Weekly 2011; 491-2. 